Article

\title{
The Business Model and Innovation Analyses: The Sustainable Transition Obstacles and Drivers for the Hospital Supply Chains
}

\author{
Catia Milena Lopes ${ }^{1, *(\mathbb{C})}$, Annibal José Scavarda ${ }^{2}$, Mauricio Nunes Macedo de Carvalho ${ }^{1,3}$ and \\ André Luis Korzenowski ${ }^{1}$ (D) \\ 1 Polytechnic School, University of Vale do Rio dos Sinos (UNISINOS), São Leopoldo 93020-190, Brazil; \\ nunesmsn@gmail.com (M.N.M.d.C.); akorzenowski@unisinos.br (A.L.K.) \\ 2 School of Production Engineering, Federal University of the State of Rio de Janeiro, Rio de Janeiro 22451-070, \\ Brazil; annibal.scavarda@unirio.br \\ 3 Production Engineering School, UNIPAMPA, Federal University of Pampa, Bagé 95413-170, Brazil \\ * Correspondence: catia.milena.lopes@gmail.com
}

Received: 15 November 2018; Accepted: 19 December 2018; Published: 23 December 2018

\begin{abstract}
This research aims to discuss the business model themes supported by the innovation regarding the sustainable transition difficulties to promote the hospital supply chains. A model for future applications and empirical analyzes in the health service area is proposed. In the current hospital scenario, the systems are characterized by the individualistic attention of the closed business models, hampering the promotion of the business models, the innovation, and the sustainable transitions as the sustainable supply chain (SSC) enablers. The survey evaluates the private hospital chain in Brazil. The model was evaluated by seven specialists indicated by the main private Brazilian hospitals that are accredited by Joint Commission International and Public Ministry. The discussion presented seeks to advance the observation and the understanding of the relationships among the business models, the innovation, the sustainable transitions, and the sustainable supply chains in the health socioeconomic context through the lens of the service provider, without exhausting these themes separately. The main results are the issues related to the difficulties of sustainable transition to promote the SSC in the hospital context, showing the elements into which the hospitals are inserted and helping to close the gap in the literature on the subject. Sustainable transitions, along with the SSC, present themselves as rich and challenging themes, but are beneficial for conducting dialogues between approaches.
\end{abstract}

Keywords: business model; innovation; sustainable transition; sustainable supply chain; hospital

\section{Introduction}

The complexity of the governance in the supply chain and its relevance to the services provided to the society are issues that deserve more attention from the research, especially considering the environmental impacts and the business models of this supply chain in the sustainable transition context. While the areas of transportation services, the food services, and the industry, in general, are already establishing the new models based on the sustainable supply chains (SSCs), the health service area still presents timid SSC results, far from the consolidated models of the incorporation of these principles in its core business models. The health sector has consistently demanded the higher attendance capacity and the rising costs. In the health governance of traditional models, there is a dissociation between the prevention and the treatment monitoring (the restoration) of the patients' condition. Alternatively or jointly, the models based on the competition (rather than the co-competition) of the agents become the fragile business models [1]. 
The economic crisis impact, the social network development, the rediscovery of favoring the sustainable idea, and the sharing-based economies create perspectives for the new business model generation [2]. The business models aim to articulate the strategy and the management and to provide evidence of how the company creates and delivers value to the stakeholders [3]. In the hospital context, there are the fragmented systems characterized by the discontinuous attention, like the closed business models, the few partnerships, and a great deal of the governmental bureaucracy [4]. In the hospitals, the business model and innovation concepts meet the needs of the solution of these fragmentations [5]. The business model vision supported by the innovation presents that the greater effectiveness in the health production improves the health system management efficiency and that it contributes to the future transitions needed to improve the future sustainability [6].

The sustainability based on the business models, on the other hand, adds a vision oriented not only on the environmental, social, and economic issues, but rather a vision projected around a value proposition for a wide range of the parties (here called the multilevel) [7]. The multilevel projection raises the concept of the shared value connected with the SSC. The SSC based on the business models adds the potential for developing the new practices, like the connected consumption or the healthcare 4.0, which emphasize the reuse of the goods, the services, and the strategies through the new connections (e.g., the peer-to-peer), redesigning the business models from the traditional economy into the sustainable transition view $[8,9]$.

Taking a more detailed view of the SSC motivation, in the opportunities to occupy the new multilevel [10], is innovative or strategic; there are ways still unknown in the business model context [3]. Christensen et al. [11] argue that the business models need to innovate and that the disruptive innovation is only a means of the SSC evolution. This innovation type not only improves the existing business models [12], but also recreates them completely differently [13,14], contributing to future transitions. However, for a better understanding of how the multilevel transitions happen, one must evaluate the business models from the multilevel perspective [15] collaborations: the niches, the regimes, and the landscape. The SSC is an approach that comprises the sustainable transition element evolution [16], so it can be considered as a new level, that is, a new multilevel perspective, called here the horizon, concentrating in a business model strategic field.

However, the transitions between the healthcare systems based on the collaboration supply chains [17] require the permanent construction of the evolution, which allows knowing the real value of the business model and the innovation proposal in the hospitals and the health system management. The collaboration niches are the organizational systems capable of bringing together the individuals and the institutions, in a democratic, participatory, and even collaborative way around the related causes. The structures flexiblely and horizontally established, and the work dynamics of the supply chains assume collaborative actions and are sustained by the will and the affinity of their members. They are characterized as significant organizational resources for the social structuring and the transitions to the future sustainability [18].

Although some hospital elements cannot be shared because of the information security and privacy (the dosage of a drug and other data), there are many opportunities for sharing in this area. The innovation and technology can transform how work can be done more efficiently and effectively, reducing the time and improving the clinical outcomes. Evaluating the sustainable transition view, the results can be interesting at the different levels, like the government, the institutions, the health plans, the suppliers, and the patients $[19,20]$. In this context, this research aims to propose a model aimed at discussing the issues related to the sustainable transition difficulties to promote the SSC in the hospital context, showing the elements into which the hospitals are inserted and helping to reduce the gap in the literature on this topic, according to the proposal of Markard [6], Gong et al. [14], and Schaltegger et al. [21], which encourage research, propose models and/or survey factors that facilitate implementation of sustainable development in business chains. 


\section{Literature Review}

This section presents some fundamental concepts about the vision of the business model and innovation concepts, the sustainable transitions supportive of the new business models and innovation, and the SSC for the improvement of the business model and innovation perspectives.

\subsection{The Business Model and Innovation Concepts in the Hospital Context}

From the 1990s, the business model term has started to receive several concepts, especially since the Internet has a strong influence on business practices [3]. The business model concept has been increasingly used to address different research questions, in different contexts, and in different management areas, without a consensus on their definition [22,23]. In this sense, although it has witnessed the business model expansion in the management of several companies and several sectors, the conceptualization of this term remains diffuse, being under discussion under the different contexts [24-27].

In the hospital context considered as a constant changes actor [21,22], the different global trends, like the population aging, the health system model personalization, the electronic health, the healthcare 4.0, and the health-oriented patients, ensure that the health systems develop the flexible business models that can be quickly adopted for the market trends $[4,11]$. However, the challenging issue of developing the hospital business models is related to not only its complicated and ever-changing nature [28], but also its intense regulation level and supply chain interaction (the suppliers, the health regulators, the health plan, and the patients) complex at different levels [11].

In most emerging developed countries, the health system is a national system that is directly regulated and administered by the government or the governmental organizations [29]. In these circumstances, having a business model appropriate for the hospitals seems extremely critical, since several stakeholders should benefit from the models [30]. In an intra-organizational perspective, a business model symbolizes what an organization believes its customers want, how they want it, and how it believes it must organize and interact with other people, to meet these needs better, and on the other hand how it will generate revenue in such a way [31]. In a larger inter-organizational context, the business models allow organizations to work in partnerships or coopetition actions [1,32], offering a joint value proposition and building multichannel supply chains [33].

However, organizational transformations have been made based on the benefits and the agility of the new technologies, providing the development of the generated new forms of the value, the creation, and the commercial transactions between the companies that see their borders expanded and expanded contributing to the business model generation [27]. From this perspective, the business models can be considered as a conceptual link among the strategy, the organizational processes, and the information systems, facilitating the communication between them and allowing the knowledge sharing [25]. Therefore, it is understandable that the business models have their greater identification in the areas of the innovation and of the technology, the strategic positioning of the organization as the value creation, the competitive advantage, and the organizational performance [27,34].

Lehoux et al. [35] examine how the business models of three Canadian health technology spinoffs sought to meet the value expectations of the clinical users and the capital investors, how the tensions were resolved, and how this impacted the health context. Janseen and Moors [36] research the business model strategies, focusing on the innovation adopted in the Dutch health sector. King and Green [37] conduct a study to understand the primary health practices in the Australian health case, focusing on the governance structure in the health sector. Faezipour and Ferreira [38] investigate the health management problems from the perspective of the patients' satisfaction and their study identifies important factors and their causal relationships that affect the patients' satisfaction, and eventually the healthcare professional social sustainable level. Nelson and Sen [39] propose a model for implementing organizational rule management in the health sector to facilitate the change of the processes and the business practices in a fast and efficient way. 
As a result, these studies identified a set of the business model elements that mediated the relationships among the business models, the hospital innovation, the value proposition, the value chain, the value capture, the governance, and the strategies. In the light of the above, these studies perceive the disruptive innovation influence of the business models, which benefit from these variables to develop new ways of creating value for the client through the organizational changes and the new business transactions $[14,26]$. In this line, over the last few years, innovation development has considered other motivations that not only deliver the solutions purely to the market. A new look at the sustainable transitions has been considered a motivating factor for the novelties with a search for the greater results. As Sousa-Zomer and Miguel [40] point out, the innovation considers the proximity to the sustainability throughout its evolution, since at the same time the problems become more sophisticated.

According to Markard et al. [6], there are several guidelines for the sustainable transition study and one of the bases for this is the national business model and innovation system. With this vision and understanding of the impact that this type of the articulation has on the contexts, the transition idea construction considers the business models and the innovation as the sustainable transition concrete bases.

\subsection{The Sustainable TransitionsSupportive of the New Business Models and Innovation}

The sustainable transition context has gained momentum in the last ten years, where several theoretical concepts have advanced the analysis of this new approach [41]. This part provides an assessment of the most prominent transition management theories that are believed to be relevant to the sustainable transition conceptual outline. For Smith et al. [42], the conception of the socio-technology or the sustainable transitions would always emphasize an explicit interest in the innovation effort direction. The sustainable transition literature deals with the possibility of managing the transition process, as discussed in Kemp et al. [10], Markard et al. [6], and Schot and Geels [16]. For Loorbach et al. [43], the transition management idea aims to influence ongoing changes in the society in terms of its speed and notably in terms of its direction.

In the hospital context, the sustainable transitions are delicate approaches, since it is difficult to relate the environmental, social, and economic dimensions to the health area context. To this end, it is desirable that in addition to the hospitals, the entire supply chain of actors guides the business models through the innovation, which helps in the sustainable transition direction, in order to create opportunities like: the reduced costs, the reduced environmental impacts, the quality gains, the strategic gains, the appropriateness of the legal part, the efficient processes, and the new technologies [44]. Within the context of transition, different trends can change the hospital's business context: social actions and service adequacy, which are based on a review of the use of corporate social responsibility and corporate social responsibility $[17,45,46]$.

Geels $[15,47]$ proposes the transition study from the multilevel perspective to the interrelated analysis: the niches, the regimes, and the landscape. In the niche perspective, it is understood that the innovation arises and is usually developed at the niche level-the micro level characterized by a company or a group of the interrelated companies. This functions as a maturing environment for the technologies still incipient to develop.

The scheme perspective is constituted by a system of the interrelated actors, in different social groups and communities, who follow a specific set of the rules. The changes that occur at the socio-technological regime level are usually slower and incremental than the changes at the niche level. The actors that constitute the existing regime have an interest in maintaining the current models for the detriment of the new ones [15].

The landscape perspective is not only defined from a wide range of external factors but related to the socio-technological regime [15]. The dimensions like the economic pressures, the cultural values, the social trends, the international conflicts, and the environmental issues are at this level. The change occurs at a slower pace, and it eventually represents the broad transitions in how the society, or part of it, acts. 
In this context, the transition idea presupposes deliberate intervention in the pursuit of the specific objectives, like these of the sustainability, and considers them socially possible, desirable, and effective. Thus, the notion that the technological development [48] would follow its course of action is rejected in this theoretical body. The responsibility for results would be contained in the social context and in the actors where the socio-technological regime is instituted, which is related to the discussion on the niche management. The transitions to more sustainable socio-technological regimes usually have a higher cost to the society, without necessarily resulting in greater immediate economic efficiency. The transitions in the socio-technological regimes in sectors like the transport, the energy, and the agrarian are the transitions that require great effort on the part of the society $[46,49]$.

In the hospital context, there is little research addressing the sustainable transitions. Broerse and Grin [50] assess the health systems' perspective on the sustainable transitions and provide an original analysis of the complex structural features of the health innovation system. Van Der Geest et al. [46] evaluate the primary healthcare from the multilevel perspective, where five levels are proposed for the primary healthcare context: the vertical organization versus the horizontal organization, the role of the medical personnel, the pharmaceutical good distribution, the traditional medicine integration, and the family planning.

Jacobsson and Bergek [51] point out that the usual sustainable policy orientation is the "market failure" approach. The environmental and social costs related to the economic performance of the current regimes are treated as negative externalities of the economic action, which would not be internalized or supported by the companies. Due to the market failures, the companies would own assets for the collective use, like the environment. The policies related to addressing the market failures are usually limited to the economic and financial taxation imposition on the companies, because of the environmental and social impacts of their economic activities.

Smith et al. [42] demonstrate the relevant governmental role of leading the transition process, acting in the structuring of the new productive systems, and the persuasion of the agents involved. They point to complements between the state and the non-state actors. They also demonstrate that, in the state-led transitions, the consumer participation has remained limited, not resulting in a major change in the system as a whole.

According to Loorbach et al. [43], the transition idea is based on its conception as a complex system, given that it depends on several agents who continually adjust their actions to the system development. The transition dynamics would be to define the critical actors and their capacity for the action/the collaboration. The problems related to the transition process are complex: They involve multiple stakeholders at different participation levels or in a larger SSC analysis.

\subsection{The Sustainable Supply Chain for the Improvement of the Business Model and Innovation Perspectives}

The SSC is concerned with the good/service management and the capital flow training, as well as the intercompany cooperation along the supply chain, focusing on the sustainable development together with all the stakeholders [20,52-54]. In this sense, the SSC is the spontaneous integration of the triple bottom line principles - the environmental, social, and economic issues-with the main inter-organizational business systems to create a coordinated supply chain, effectively managing in short- and long-term stakeholder requirements and the competitiveness and resilience of the organization.

The concept evolution, which bridges the supply chain traditional view with the sustainability $[55,56]$, has shown greater clarification and concern with the macro change context, since its definition became more complex in the better adaptation to the changes in the market. This concept was given a greater emphasis by the work of Seuring and Müller [52], based on the results of an extensive literature review, in which the authors identify the need to treat the three triple bottom line dimension integration in a strategic and aligned fashion with the supply chain scope. In this way, the SSC is understood as "the management of capital flows, materials, and information, as well as the cooperation between 
the companies along the supply chain, aiming at the three dimensions: environmental, social, and economic, which are requirements of the customers and the stakeholders" [52,56].

In a similar vein, Pagell and $\mathrm{Wu}$ [57] present their contributions related to the theme, stating that the SSC should consider a good performance both in the traditional measures of the gains and the losses, as well as on the expanded performance with the inclusion of the environmental and social dimensions. Thus, if an SSC is one that performs well in all the Triple Botton Line (3BL) elements, then the management of these supply chains refers to specific actions (managerial decisions and/or behaviors) taken to make the supply chain more sustainable. The environmental and social aspects must be linked to the decision-making on the supply chain strategies [57].

Beske [58], on the other hand, elucidate four main categories that would be essential to work on the SSC concept being: the orientation, the supply chain continuity, the risk management, and the proactivity. Thus, the orientation of the organizations is divided into three questions: the orientation towards the sustainability [56], the orientation related to the main management of the organizations through the commitment to develop the sustainable strategies for the supply chain, and the orientation towards the disposition to learn the new knowledge [32]. The second category refers to the continuity of the supply chain in relation to the practices of the cooperation and the integration, from the establishment of the long-term relationships with the suppliers and the customers. The third category concerns the risk management, where organizations must identify, reduce, and eliminate the risk through the continuous practices, based on the commitment of the long-term relationships, the partner development, and the monitoring activities. In developing these relationships, the supply chain can be provided with a pro-active condition in relation to the necessary innovation, thus contemplating the fourth category of the analysis in the SSCs $[52,58]$.

Among the results of the integration of the socio environmental practices in the organizations, there is the competitive advantage conquest, debated by many authors in the area. Some examples of the business differentiation can occur with the business development like the "best practices" [32,56], the new business models [59], the cost reduction [60], and the social legitimation [61,62]. However, the main reason for the competitive advantage creation comes from the integration and the inter-organizational collaborative relationships that emerge in the supply chains [62-64].

In this sense, Carter and Rogers [65] identify four SSC facilitators:

1. The strategy - the holistic and purposeful identification of the individual SSC initiatives that align and support the organization's overall sustainable strategy;

2. The risk management-it includes the contingency planning for both upstream and downstream supply chains;

3. The organizational culture-it is deeply rooted and encompasses the organizational citizenship, which includes the high ethical standards and the expectations (a foundation for the SSC), along with the respect for the society (both inside and outside the organization) and the natural environment; and

4. The transparency-it is in terms of the engagement and the proactive communication with the key stakeholders and the traceability and the visibility in the upstream processes and the downstream supply chain operations.

In this research, Carter and Rogers [65] concept is used for the sustainability, which is defined as "the transparent strategic integration and achievement of the environmental, social, and economic objectives of the organization in the systemic coordination of the main inter-organizational business processes to improve the long-term economy of the individual enterprise and its supply chains", to develop the proposed model.

\section{Methodology}

For this research, a basic understanding of the relationship between the business models was developed and some basic ideas were formulated on how the companies could actively influence the 
evolution processes for the sustainable transitions that promote the SSC. To do this, we combined the insights from the existing literature related to the business models, the innovation, the sustainable transitions, and the SSC.

The selected research method comprises two main steps. The first step is the construction of a model to evaluate the determinant relationships in the hospital context by reviewing the literature review and the authors' judgments. This step is related to the objective of analyzing the external aspects and the dimensions about the business models and the innovation with a focus on the sustainable transitions and the SSC. There is vast literature on the business models and the innovation, but for the sustainable transition and SSC topics, there is little literature, especially in the hospital context. The literature review was carried out from the databases: Science Direct, Scopus, Scielo, Elsevier and PubMed. Theoretical survey permeated the hospital context, analyzing the business models, the innovation, the sustainable transitions, the SSC, and the hospital processes associated with these concepts. It used a series of the general works and the literature reviews $[4,5,15,25,47]$ to derive the main trends and characteristics of the transformative strategies. In this paper, we proposed to understand the development described from the sustainable transition perspective, based on the literature on the transitions and their dynamics $[6,43,48,66]$. In doing so, we abstracted a conceptual model that describes the business model and innovation evolution process to promote the sustainable transitions [43] and the SSC enablers.

The second step is the validation of this model with the hospital specialists. This step aims to propose a model for future applications to discuss the topics under the evaluation of the experts from the hospital area in Brazil. To invite the specialists, we first sought the main private hospitals in Brazil that practice sustainability actions. In this way, the research of Machado et al. [67], which evaluated nine Brazilian hospitals accredited by Joint Commission International (JCI) and recognized by the Ministry of Health, which considers in its strategic planning, mission, vision and values, actions related to sustainability. Each of these nine hospitals was asked to appoint a specialist. The experts were invited to participate, considering the following criteria: academic training, publication of academic papers on related subjects (business models, innovation management, health quality, health innovation, and health services); and managerial experience in hospitals. Seven experts agreed to participate in the study. The interviews were conducted individually (Table 1). The interviews were typical sources of the data in qualitative studies. The semi-structured interviews refined and evaluated the proposed model. The relatively open format encouraged the respondents to express their opinions in relation to other standard techniques, like the use of the questionnaires [68].

Table 1. Experts' interviews.

\begin{tabular}{lcccc}
\hline Expert's & Professional Position & Years of Experience & Education & Hospital \\
\hline Expert 1 & Controller Manager & 15 years & Master & Private \\
Expert 2 & Quality Coordinator & 20 years & Ungraduate & Private \\
Expert 3 & Financial Manager & 10 years & Specialist & Private \\
Expert 4 & Operations Manager & 19 years & Master & Private \\
Expert 5 & Manager of Supply Chain & 11 years & Specialist & Private \\
Expert 6 & Marketing Supervisor & 8 years & Specialist & Private \\
Expert 7 & Services Manager & 12 years & Master & Private \\
\hline
\end{tabular}

The interviews were recorded in audio and followed the protocol of sending the material (the question guide, Table 2) in advance by email to be analyzed by each specialist before the interview. They analyzed the proposed health model and evaluated the impact factors in relation to the health services, managing the innovation to improve the healthcare quality and its sustainable implications. Each specialist discussed each topic presented by the researchers. Immediately after the interviews, the researchers transcribed and reviewed the records. The respondents were contacted to clarify details to ensure the correct transcript understanding [68]. 
Table 2. The key questions of the interviews.

\begin{tabular}{l}
\hline I) What is the hospital's business model? How has it developed over time? What are the latest changes? How and why did they happen? \\
II) What is the impact of governance on business models? \\
\hline III) What is the impact of technology on business models? \\
\hline IV) What impact does quality generate on business models? \\
\hline V) What is the impact of external context strategies on business models? \\
\hline VI) How do you relate business models to innovation? \\
\hline VII) What does the hospital expect when considering innovation in the business model (if there is an integrated approach)? What are the \\
expected results of the different innovations? Are there success stories and failure cases that can illustrate this relationship? How did \\
they behave? Why were they satisfactory or not? \\
\hline VIII) Are there moves in business models that aim at a transition to sustainability in the hospital context? \\
\hline IX) What does the hospital expect when it considers sustainability in the business model (if there is an integrated approach)? What are \\
the expected results of the different sustainable actions in the business? Are there success stories and failure cases that can illustrate this \\
relationship? How did they behave? Why were they satisfactory or not? \\
\hline X) Assessing the context in which hospitals are embedded, is it possible to determine which key actors interfere with business models? \\
\hline XI) In the context of the actors, it is possible to determine that an actor can influence their relationship network/partnerships? What are \\
the possible influences that can be generated? \\
\hline XII) Does the relationship determined by the set of actors generate benefits or not within its centrality? \\
\hline XIII) Within the idea of governance, does governance exist within this set of actors? Are there examples? \\
\hline XIV) Is it possible that sustainable supply chain may exist within this network of actors? Are there successes and failures to illustrate \\
these partnerships? What are the key benefits expected?
\end{tabular}

The data from the interviews were compiled through the content analysis, which is a classic method of the data analysis of the interviews [68]. The content analysis was carried out with the support of the NVivo software (version 11). The results were qualitatively analyzed and compared with the evidence found in the literature to allow for the information conversion from both sources in the improvements in the models.

\section{Results}

Authors should discuss the results and how they can be interpreted in the perspective of previous studies and of the working hypotheses. The findings and their implications should be discussed in the possible broadest context. Future research directions may also be highlighted.

\subsection{The Proposal of a Model to Assess the Business Models and the Innovation from the Perspective of the Sustainable Transitions and the Enablers for the Sustainable Supply Chain in the Hospitals}

Over the last decade, the business models supported by the innovation have sought to promote a new multilevel, in which they bring solid results not only to a company but to the supply chain of actors. In this way, the practices that use the transition dynamics understanding to influence the speed and the direction of the changes with the SSC vision were started [41,43].

The health services have been considered valuable resources that have faced a number of transitional initiatives over the past decades [69]. These transitions have been primarily used to manage the high development cost and to raise the quality standards and the need for legal (environmental and social) adequacies, presenting the challenges to the existing health business models, and the scenario involving the hospitals requires a new way of thinking strategically to ensure the sustainability [70], especially in the emerging countries.

On the one hand, considering the importance of the hospital services rendered to the society, the hospitals need a model driven by the innovation in order to support the increase of the demand in a way that does not harm the future generations. In this sense, there are already initiatives in the health area like the innovation based on the internet of things [71], the healthcare 4.0 [71,72], and the healthcare big data analytics [73].

On the other hand, evaluating the sustainable transition level that the hospitals must cover, not only should the questions of the new technologies, practices (clinics) or management be included, but rather should focus on the business models to promote the sustainability [74] and share actions 
in a larger supply chain like the SSC. One of the main challenges in the hospitals is to ensure the success of a business model, combining it with a wider scope, that is, in the perspective landscape. In the landscape dynamics, the gain is larger and more comprehensive, generating environmental [9], social [32,62], economic [46], quality [75], strategic [14,76] and technological [76] benefits to provide a new multilevel horizon that works collaboratively [77].

The innovation has multiplied the business model types, in contrast to the traditional economy, where the business model variety is smaller $[25,78]$. The shared economy presents enormous possibilities for the new business model created through the integration [19]. In this way, in the shared economy, most business models are made up of the supply chain/platforms, that is, the companies that carry out their business transactions with the partners and the consumers [78]. Oftelie [79] assesses resource utilization, and reports the SSC can reduce environmental impact, and reduce operational costs through resource sharing such as surgical equipment like New York's Cohealo, the US, which leases the hospital equipment to the hospitals.

In the hospital context, the sustainability is a delicate approach, since it is difficult to reconcile the environmental, social, and economic dimensions with the health area context [68]. To this end, it is desirable that in addition to the hospitals, the entire supply chain of actors should orient the business models through the innovation to help guide the sustainable transitions [80], in order to create the opportunities like the cost reduction, the environmental impacts, the quality gains, the strategic gains, the legal part appropriateness, the efficient processes, and the new technologies [2].

In this sense, with the business model development oriented in the strategies of the sustainable transitions and the SSC, as the cited example of the company Cohealo in the health area, both the hospitals as well as the related actors have significant gains. On the one hand, the stakeholder supply chain reduces the impact on its internal processes, i.e., the hospitals with reduced operational costs (the economic dimension), reduces the use of the water, the energy, and the materials (the environmental dimension) and increases the supply of the services provided by the increase of the operational focus (the social dimension). On the other hand, the business models in which it has a vision of the shared actions for the sustainable transitions and that promote new businesses are also framed in the SSC concept.

The concept exploration related to the business models supported by the innovation in the hospital context provided support for the proposed model design. The authors of this paper sought to characterize the aspects present in the hospital sector, covering the external environment, the main actors that have an influence on the business model processes of the hospitals were considered: the suppliers, the legal regulators, the health plans, and the patients, which permeate this whole context. However, in the internal hospital context, the highlights in relation to the interaction with the business models and the innovation were revealed.

The main objective of the model (Figure 1) is to demonstrate the elements into which the hospitals are inserted, as a result of the business model and innovation approach and the sustainable transitions as ways to enable the hospital vision.

The transition conceptual idea, a heuristic, was used to explore the possible changes and the possibilities to influence these changes to the SSC. Hence, the starting point is not just the hospitals' desired goal, but the process to better make collective sense of the complex changes in which the business is a part. In other words, the model provides a way to structure thinking and debate about ongoing evolutionary changes and thus to take the coordinated action to deal with these possible changes so that it enables the SSC. In the literature that discusses the business model approach supported by the innovation as a means of the transitions, this nuance, often overlooked, comes in the face of the simplified sustainable transitions approach to the oriented planning [2] for a simplistic view.

The sustainable transition multilevel perspective provides an analysis of how the transition process is not linear. It is observed that the interaction of the developments is generated in three analytical levels: the niches (the business model locus), the regimes (the locus of the established practices and the associated rules that stabilize the existing systems through the innovation), and the 
external socioeconomic situation which is the landscape [15]. As a contribution of this model, a new level that is the horizon, which resulted from the integration of the internal environment (the niches and the regimes) with the external environment (the landscape) was added. Each level refers to a heterogeneous configuration of the elements. The highest levels (the landscape and the horizon) are more stable than the lower levels in terms of the number of the factors and the degrees of the alignment between the elements.

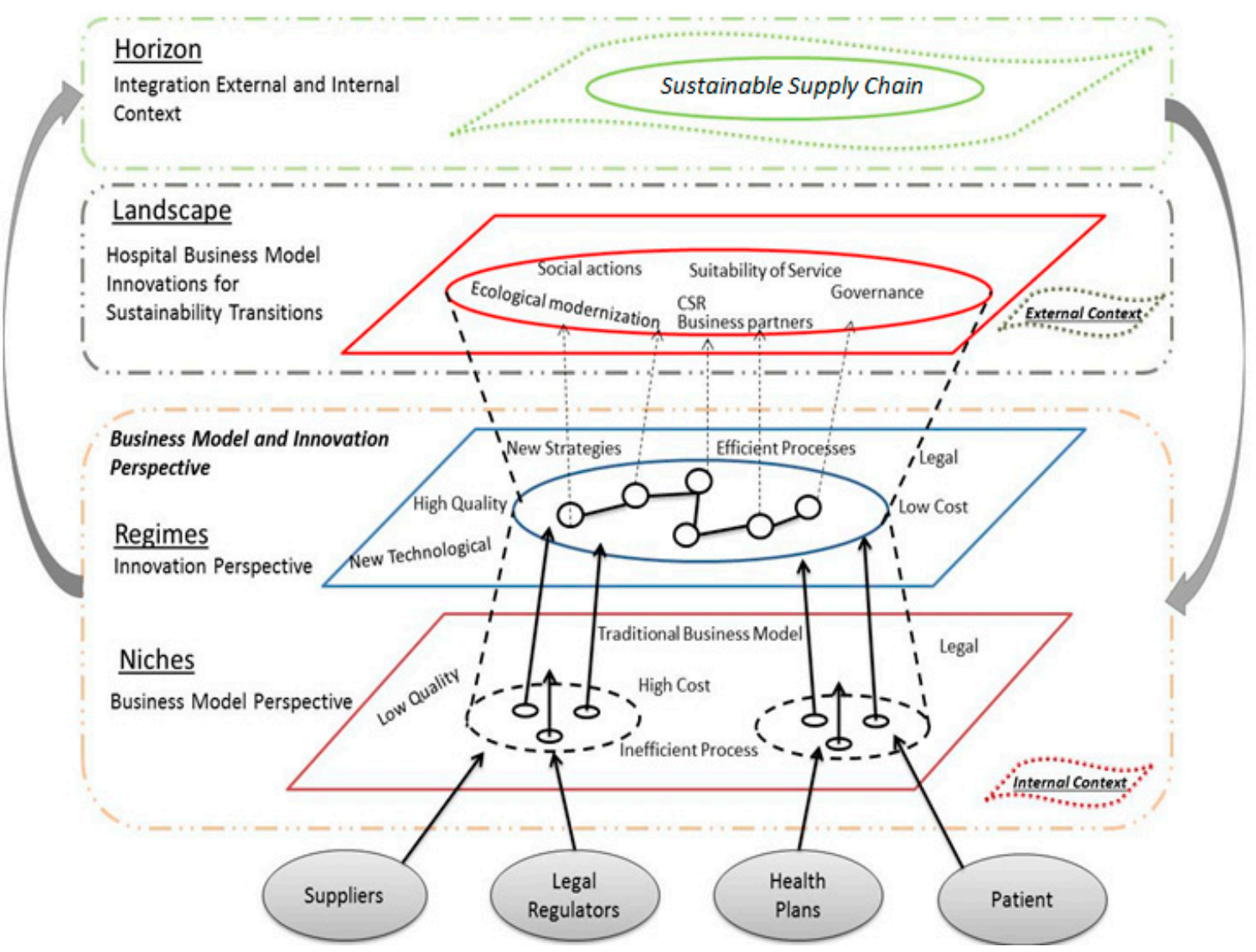

Figure 1. The proposed model for the evaluation of the experts.

However, to reach the multilevel horizon, one must structure the business models of each actor in the health supply chain for this vision. In this sense, the business models (the multilevel niches) must be supported by the well-structured strategies and the technological, service, organizational, social and cultural multilevel regimes, extending to a multilevel landscape vision). The multilevel landscape aims to generate actions for the supply chain of actors, through the business partnerships, the governance, and the social responsibility that generates social actions, ecological and the sustainability of the services. However, only with the maturation of the set of the actions at all multilevel is the fact that one can achieve the multilevel horizon SSC.

\subsection{The Experts' Analysis}

As presented previously, seven experts met the requirements set out in the research methodology. Through the evaluation of the specialists, we sought a complementary view on the proposed model that allows discussing the issues arising from the business models and the innovation regarding the sustainable transition difficulties to promote the SSC in the hospital context.

Concerning the business models supported by the hospital vision, all experts pointed out that, in the last ten years, both the health area as well as the hospitals have had significant changes in their business models [81]. Among the main reasons for these changes were: the alignment with the service 
quality (the certifications/the accreditations and the government regulations), the new technologies, and the paradigm shifts in the market, according to Nelson and Sen's [39]. When specifically asked about the business models currently used by the private hospitals, Expert 1, Expert 3, and Expert 4 commented that the model is traditional, called Fee-For-Service. Most of the main Brazilian private hospitals are dependent on health plans, that is, it is the largest payment source. These experts pointed out that, in some cases, a single-source payer can account for between $40 \%$ and $60 \%$ of all the billing of a single hospital. In this sense, the relationship between the hospitals and the health plans may suffer pressures in which it may be detrimental to the business model progress focused on the sustainability, and the feasibility of providing the health service, or even generate the patients' questions.

The seven specialists analyzed the business model dimensions: the governance, the technology, the quality, and the strategy within the hospitals and the supply chain of actors. In the governance dimension, Expert 1, Expert 3, and Expert 7 emphasized that the health area in Brazil is regulated by the National Agency of the Supplementary Health (ANS), the National Health Surveillance Agency (ANVISA), and the associations like the Federal Medical Council (CRM), in which these institutions limit the rules between the hospitals and the paying source. In some cases, it generates conflicts between these actors, and for many times, it can impact the business model evolution, in the retrospective (see Lehoux et al. [35], Osterwalder et al. [26], and Zott et al. [27]).

In the technological dimension, Experts1-7 have pointed out that it is one of the most active dimensions in the hospitals, since it deals with the innovation and the quality improvement in the service delivery and could be an evolutionary strategy for the hospital business models, according to Zott et al. [27]. However, on the other hand, for many times, it is not possible to innovate technologically in the service quality, since it is not a common strategy between the hospital actors and the health plans, due to the service cost increase, as examples cited, was the question of the surgical robot, which generates so many operational benefits (the cost reduction) as well as the health promotion for the patients, but due to the high investment, in Brazil, there are many hospitals with this technology. Expert 2, Expert 3, and Expert 5 have pointed out that there is a mismatch between the medical technological evolution used by the hospitals, in relation to the technology lack in the operational activities, like the care, and the supply chain, where the processes are mostly manual and very bureaucratic, as the approach of Nelson and Sen [39].

In the quality dimension, both experts emphasized the importance of the development of this dimension, due to the hospitals' end-activity. Expert 2 and Expert 7 stressed the importance of the hospitals seeking quality accreditation at an international level. Expert 1 and Expert 3 have pointed out that to accredit quality internationally is a business strategy, because of its high implementation cost, but the returns are satisfactory due to the improved operational and service activities. Expert 1 and Expert 7 also commented that the quality should be related to the remuneration model. The higher the quality of the processes and the services (the indicators), the higher the quality in the processes in order to bring a better financial return with smaller impacts on the environmental sustainable issue and greater social sustainability.

For the strategic dimension, they all stressed that the current business model generates a lot of the bureaucracy, in which it directly impacts the development of the market strategies and the partnerships, according to Loorbach et al. [43]. Only the large players in the supply chain of actors are able to develop the consolidation strategies in some health areas like the diagnosis, the imaging, and the cancer. The experts emphasized the importance of the hospitals having a well-defined supply chain of actors (the partners), as this helps them to jointly develop strategies (the model's SSC vision) focused on the quality improvements, the compliance with the laws and the regulations, and the processes governance needed to deliver the health services, according to Broerse and Grin [50].

When asked about the question of the sustainability, the experts pointed out that the hospitals are beginners in this area. Expert 1 stressed that the main sustainable dimension evaluated is the economic and secondly social, due to the care part. However, in the last few years, the hospitals have begun to evolve in the actions for the environmental sustainable development. Expert 6 commented that 
the question of the sustainability is widely used to promote the hospitals (the image), but that few institutions have it well developed in their business model strategies to promote the sustainability in the three pillars: the economic, social, and environmental ones, by Smith et al. [42], Loorbach et al. [43], and Van der Geest et al. [46], respectively.

The evaluation of the specialists considered the proposed model with a future vision since both stressed that, in the current business models in the hospital context, there is not a clear interaction of the partnerships, that is, the SSC vision. For Expert 1, the supply chain of the interaction is more developed in some punctual projects, for example, the innovative project being tested in Brazil the introduction of the Diagnosis Related Group (DRG) in the commercial tables. The experts emphasized the importance of this project for Brazil, because it is an innovation process, through the SSC that is lacking in the Brazilian health system. This DRG payment system is already widely used in the United States and in Europe. The DRG project mainly links the issues of the governance and the legitimacy, the business models for the healthcare 4.0, and the SSC mostly for the sake of the transparency, the cost reduction, and the efficiency and quality increase in the services provided. In Brazil, it has not yet been possible to evolve, because the supply chain of actors is not aligned (not being collaborative), as highlighted by the expert's lack of the confidence and the clear strategies in the supply chain impacts on the new horizon evolution focused on the SSC.

Among the major obstacles raised by the business model evolution specialists for the SSC was lack of the clear strategies for staggering the sustainable transitions between the supply chain of actors. Expert 1, Expert 3, Expert 6, and Expert 7 pointed out that the health costs are increasing and are tending to be increasing, particularly due to the technological evolution and the non-monitoring of the revenue, thus bringing the current business models closer to their end. Fort Expert 4 and Expert 5 , the technology applied to the health should and must continue to develop until the health area finds the resources to diagnose and to treat all the human diseases. In an overview of the experts, the hospitals, both public and private, already show strong exhaustion signs. Thus, the business models tend to evolve to a level of resource sharing, not only the financial resource, but also the technological, human, knowledge, and material resources [8,82].

Finally, the experts judged the proposed model from a theoretical and practical point of view, with the clarity of the concepts and the relevance to the fulfillment of the research objectives.

\section{Conclusions}

The business model and innovation contexts [83] for the sustainable transitions that enable the SSC in the hospital context are still unexplored issues $[41,84]$. Since the research on these topics does not occur frequently, it is difficult to build large databases that can be analyzed to determine the correlations between them. On the one hand, the business models, the innovation, and the sustainable transitions are complex research topics [85]. The researchers tend to disagree on how best to investigate them. However, the present research sought to discuss the business model and innovation themes regarding the sustainable transition difficulties to promote the SSC in the hospital context and to propose a model for the future applications and the empirical analysis in the health services.

The hospitals are recognized as complex organizations, due to the different interactivity between the actors [4] that interact with the hospital systems: the suppliers, the legal regulators, the health plans, and the patients. For many times, this interactivity between the actors cannot establish the equal gains, that is, the different needs of each actor interfere in the hospital business models and whether there is even the issue of the sustainable transitions and the SSC of the supply chain as a whole [6].

The SSC has potential for the business model and innovation developments, especially when in synergy with the sustainable transitions. However, for this to happen, it is necessary that the environmental, social, and economic benefits become more widespread with the supply chain of actors and the society. Nowadays, it is observed that the ignorance about the shared economy makes it mistakenly confused with the social economy. However, both concepts have different proposals, while the shared economy aims to promote the sharing and the reuse of the goods, the services, and 
the mutual gains [82], the social economy has a principle the activity development to achieve the social goals.

In this way, it perceives the need for an evolution in the business models and the innovation [26] for the sustainable transitions in the hospital context that elevates to the SSC in the supply chain of actors [79]. This vision is in line with the guidelines of the hospitals to ensure the success of their business models and innovation, the balance, the competitiveness, and the value delivery to the population [85] and the sustainable transitions with the SSC horizon. Thus, solutions should not only include some actors or levels, like only questions of the new technologies, the practices (the assistance), and the management but rather of actors linked by the innovation-driven business models to perhaps also bring gains in the sustainable dimensions.

The proposed model aimed at discussing the issues related to the sustainable transition difficulties to promote the SSC in the hospital context, showing the elements into which the hospitals are inserted and helping to reduce the gap in the literature on this topic. Sustainable transitions with the SSC vision present rich and challenging topics, but are beneficial for conducting dialogues between approaches $[8,15]$, and governance-driven business models, as well as the direction for a broader view. for health care 4.0.

However, it should be pointed out that the discussion was not intended to conduct a thorough issue examination, but rather to demonstrate that the relationships can be realized and better observed in the social context. From the whole discussion, it is understood that the present research meets its proposed objective since it approached the business model concept evolution supported by the innovation that can contribute with the sustainable transition movement, if there is the construction of a new horizon for promoting the SSC. Regarding the limitations of this research, it highlights the amount of specialists who participated. Another limitation is the nature of the hospital chain is so complex that its sustainability transition is based on significant changes in business models, which in turn are heavily influenced by innovation. Therefore, business models face challenges: overcoming the barriers, lacking connection between the chain's business models and contributing to the creation of visions and the expectations of a diverse set of related parties. Already in the construction of movements for transition, the need of interactions between the actors of the chain is perceived, so that the Multiple Level Perspective (MLP) can be realized. There are still many issues to understand better about the MLP, such as: the role of each actor for transitions, power relations between actors at each multiple level and the difficulty of operationalization.

Facing the exposed contributions and limitations, it is suggested that the proposed framework be used as the basis for future research. A suggestion of future research could assess the influences between the internal and external contexts and the influences between actors and MLP levels in the hospital context. Another suggestion is further research and application of potential outputs for the transition to sustainability for health organizations based on their business models and adopted innovations.

One suggestion is a broad field of research to be carried out on business models supported by innovation through the strategy that promotes transitions to sustainability as an enabler in the context of the hospital chain $[6,12,45]$. It is expected that the proposed framework contributes to new discussions within this thematic and context of the hospital chain. In this perspective, it is recommended as future research, to examine case studies of hospitals that are in a process of remodeling their business model, and identify the difficulties encountered in the process of evolution to reach the horizon level.

Finally, there is a broad research area to be carried out in the business models supported by the innovation through the strategy that promotes the sustainable transitions as enablers for the SSC in the hospital context [6]. It is hoped that the proposed model contributes to the new discussions within this theme and the hospital context. In this perspective, it is recommended as the future research studies, to examine the case studies of the hospitals that are in the process of remodeling their business models and to identify the difficulties encountered in the evolution process to reach the SSC. 
Author Contributions: Writing: C.M.L.; providing case and idea: C.M.L., A.J.S.; providing revised advice: M.N.M.d.C. and A.L.K.

Funding: This research received no external funding.

Conflicts of Interest: The authors declare no conflicts of interest.

\section{References}

1. Christensen, C.M.; Overdorf, M. Meeting the challenge of disruptive change. Harvard Bus. Rev. 2000, 78, 66-77.

2. Boons, F.; Lüdeke-Freund, F. Business models for sustainable innovation: State-of-the-art and steps towards a research agenda. J. Clean. Prod. 2013, 45, 9-19. [CrossRef]

3. Osterwalder, A.; Pigneur, Y. Business Model Generation; John Wiley \& sons: Hoboken, NJ, USA, 2010.

4. Bohrer, C.T.; Vargas, E.R. Innovation in hospital services from a perspective of technical operations: Case studies in university hospitals. In Proceedings of the 7th International Conference on Innovation \& Management, Wuhan, China, 4-5 December 2010.

5. Amit, R.; Zott, C. Creating value through business model innovation. MIT Sloan Manag. Rev. 2012, 53, 41-42.

6. Markard, J.; Raven, R.; Truffer, B. Sustainability transitions: An emerging field of research and its prospects. Res. Policy 2012, 41, 955-967. [CrossRef]

7. Daunorienè, A.; Drakšaitè, A.; Snieška, V.; Valodkienè, G. Evaluating sustainability of sharing economy business models. Procedia Soc. Behav. Sci. 2015, 213, 836-841. [CrossRef]

8. Dubois, E.; Schor, J.; Carfagna, L. Connected consumption: A sharing economy takes hold. Rotman Manag. 2014, 50-55.

9. Manga, V.E.; Forton, O.T.; Mofor, L.A.; Woodard, R. Health care waste management in Cameroon: A case study from the Southwestern Region. Resour. Conserv.Recycl. 2011, 57, 108-116. [CrossRef]

10. Kemp, R.; Schot, J.; Hoogma, R. Regime shifts to sustainability through processes of niche formation: The approach of strategic niche management. Technol. Anal. Strat. Manag. 1998, 10, 175-198. [CrossRef]

11. Christensen, C M.; Horn, M.B.; Johnson, C.W. How Disruptive Innovation Will Change the Way We Learn; Education Week: Bethesda, MD, USA, 2008; Volume 27, pp. 25-36.

12. Mathivathanan, D.; Kannan, D.; Haq, A.N. Sustainable supply chain management practices in Indian automotive industry: A multi-stakeholder view. Resour. Conserv. Recycl. 2018, 128, 284-305. [CrossRef]

13. Balck, B.; Cracau, D. Empirical Analysis of Customer Motives in the Shareconomy: A Cross-Sectoral Comparison; University Magdeburg: Magdeburg, Germany, 2015.

14. Gong, M.; Simpson, A.; Koh, L.; Tan, K.H. Inside out: The interrelationships of sustainable performance metrics and its effect on business decision making: Theory and practice. Resour. Conserv. Recycl. 2018, 128, 155-166. [CrossRef]

15. Geels, F.W. Technological transitions as evolutionary reconfiguration processes: A multi-level perspective and a case-study. Research Policy 2002, 31, 1257-1274. [CrossRef]

16. Schot, J.; Geels, F.W. Strategic niche management and sustainable innovation journeys: Theory, findings, research agenda, and policy. Technol. Analy. Strateg. Manag. 2008, 20, 537-554. [CrossRef]

17. Geels, F.W. Ontologies, socio-technical transitions (to sustainability), and the multi-level perspective. Res. Policy 2010, 39, 495-510. [CrossRef]

18. Lozano, R. Envisioning sustainability three-dimensionally. J. Clean. Prod. 2008, 16, 1838-1846. [CrossRef]

19. Gansky, L. The Mesh: Why the Future of Business Is Sharing; Penguin: New York, NY, USA, 2010.

20. Lin, K.P.; Tseng, M.L.; Pai, P.F. Sustainable supply chain management using approximate fuzzy DEMATEL method. Resour. Conserv. Recycl. 2018, 128, 134-142. [CrossRef]

21. Schaltegger, S.; Hansen, E.; Lüdeke-Freund, F. Business models for sustainability: Origins, present research, and future avenues. Organ. Environ. 2016. [CrossRef]

22. Dou, Y.; Togawa, T.; Dong, L.; Fujii, M.; Ohnishi, S.; Tanikawa, H.; Fujita, T. Innovative planning and evaluation system for district heating using waste heat considering spatial configuration: A case in Fukushima, Japan. Resour. Conserv. Recycl. 2018, 128, 406-416. [CrossRef]

23. Zott, C.; Amit, R.; Massa, L. The business model: Recent developments and future research. J. Manag. 2011, 37, 1019-1042.

24. Shafer, S.M.; Smith, H.J.; Linder, J.C. The power of business models. Bus. Horiz. 2005, 48, 199-207. [CrossRef] 
25. Osterwalder, A.; Pigneur, Y. Modeling value propositions in e-Business. In Proceedings of the 5th international conference on Electronic commerce-ICEC '03, Pittsburgh, PA, USA, 30 September-3 October 2003; ACM Press: New York, NY, USA, 2003; pp. 429-436.

26. Osterwalder, A.; Pigneur, Y.; Tucci, C.L. Clarifying Business Models: Origins, Present and Future of the Concept. Commun. Assoc. Inf. Syst. 2005, 16, 1-29. [CrossRef]

27. Zott, C.; Amit, R.; Massa, L. The Business Model: Theoretical Roots, Recent Developments, and Future Research; IESE Business School: Barcelona, Spain, 2010.

28. Gallouj, F.; Weinstein, O. Innovation in services. Res. Policy 1997, 2, 537-556. [CrossRef]

29. Hwang, J.; Christensen, C.M. Disruptive innovation in health care delivery: A framework for business-model innovation. Health Aff. 2008, 27, 1329-1335. [CrossRef] [PubMed]

30. Pfannstiel, M.A.; Rasche, C. Service Business Model Innovation in Healthcare and Hospital Management; Springer Science and Business Media: Berlin, Germany, 2017.

31. Teece, D.J. Business models, business strategy and innovation. Long Range Plan. 2010, 43, 172-194. [CrossRef]

32. Ahmadi, H.B.; Kusi-Sarpong, S.; Rezaei, J. Assessing the social sustainability of supply chains using best worst method. Resour. Conserv. Recycl. 2017, 126, 99-106. [CrossRef]

33. Salge, T.O.; Kohli, R.; Barrett, M. Investing in information systems: On the behavioral and institutional search mechanisms underpinning hospitals is investment decisions. Mis. Q. 2015, 39, 61-90. [CrossRef]

34. Woolridge, A.; Morrissey, A.; Phillips, P.S. The development of strategic and tactical tools, using systems analysis, for waste management in large complex organisations: A case study in UK healthcare waste. Resour. Conserv. Recycl. 2005, 44, 115-137. [CrossRef]

35. Lehoux, P.; Daudelin, G.; Williams-Jones, B.; Denis, J.L.; Longo, C. How do business model and health technology design influence each other? Insights from a longitudinal case study of three academic spin-offs. Res. Policy 2014, 43, 1025-1038. [CrossRef]

36. Janssen, M.; Moors, E.H. Caring for healthcare entrepreneurs-towards successful entrepreneurial strategies for sustainable innovations in Dutch healthcare. Technol. Forecast. Soc. Change 2013, 80, 1360-1374. [CrossRef]

37. King, R.; Green, P. Governance of primary healthcare practices: Australian insights. Bus. Horiz. 2012, 55, 593-608. [CrossRef]

38. Faezipour, M.; Ferreira, S. A system dynamics perspective of patient satisfaction in healthcare. Procedia Comput. Sci. 2013, 16, 148-156. [CrossRef]

39. Nelson, M.L.; Sen, R. Business rules management in healthcare: A lifecycle approach. Decis. Support Syst. 2014, 57, 387-394. [CrossRef]

40. Sousa-Zomer, T.T.; Miguel, P.A.C. Sustainable business models as an innovation strategy in the water sector: An empirical investigation of a sustainable product-service system. J. Clean. Prod. 2016. [CrossRef]

41. Grin, J.; Rotmans, J.; Schot, J. Transitions to Sustainable Development: New Directions in the Study of Long Term Transformative Change; Routledge: London, UK, 2010.

42. Smith, A.; Voß, J.P.; Grin, J. Innovation studies and sustainability transitions: The allure of the multi-level perspective and its challenges. Res. Policy 2010, 39, 435-448. [CrossRef]

43. Loorbach, D.; Frantzeskaki, N.; Thissen, W. A transition research perspective on governance for sustainability. In European Research on Sustainable Development; Springer Berlin Heidelberg: Heidelberg, Germany, 2011; pp. 73-89.

44. Hekkert, M.P.; Negro, S.O. Functions of innovation systems as a framework to understand sustainable technological change: Empirical evidence for earlier claims. Technol. Forecast. Soc. Change 2008, 76, 584-594. [CrossRef]

45. Russo, F. What is the CSR's focus in healthcare? J. Bus. Ethics 2016, 134, 323-334. [CrossRef]

46. Van der Geest, S.; Speckmann, J.D.; Streefland, P.H. Primary health care in a multi-level perspective: Towards a research agenda. Soc. Sci. Med. 1990, 30, 1025-1034. [CrossRef]

47. Geels, F.W. From sectoral systems of innovation to socio-technical systems: Insights about dynamics and change from sociology and institutional theory. Res. Policy 2004, 33, 897-920. [CrossRef]

48. Shove, E.; Walker, G. CAUTION! Transitions ahead: politics, practice, and sustainable transition management. Environ. Plan. A 2007, 39, 763-770. [CrossRef]

49. Geels, F.W.; Hekkert, M.P.; Jacobsson, S. The dynamics of sustainable innovation journeys. Technol. Anal. Strateg. Manag. 2008, 20, 521-536. [CrossRef]

50. Broerse, J.; Grin, J. Toward Sustainable Transitions in Healthcare Systems; Taylor\& Francis: Abingdon, UK, 2017. 
51. Jacobsson, S.; Bergek, A. Innovation system analyses and sustainability transitions: Contributions and suggestions for research. Environ. Innov. Soc. Transit. 2011, 1, 41-57. [CrossRef]

52. Seuring, S.; Müller, M. From a literature review to a conceptual framework for sustainable supply chain management. J. Clean. Prod. 2008, 16, 1699-1710. [CrossRef]

53. Carter, C.R.; Easton, L.P. Sustainable supply chain management: Evolution and future directions. Int. J. Phys. Distrib Logist. Manag. 2011, 41, 46-62. [CrossRef]

54. Viani, C.; Vaccari, M.; Tudor, T. Recovering value from used medical instruments: A case study of laryngoscopes in England and Italy. Resour. Conserv. Recycl. 2016, 111, 1-9. [CrossRef]

55. Kleindorfer, P.R.; Singhal, K.; Wassenhove, L.N. Sustainable operations management. Prod. Oper. Manag. 2005, 14, 482-492. [CrossRef]

56. Zhang, M.; Tse, Y.K.; Doherty, B.; Li, S.; Akhtar, P. Sustainable supply chain management: Confirmation of a higher-order model. Resour. Conserv. Recycl. 2018, 128, 206-221. [CrossRef]

57. Pagell, M.; Wu, Z. Building a more complete theory of sustainable supply chain management using case studies of 10 exemplars. J. Supply Chain Manag. 2009, 45, 37-56. [CrossRef]

58. Beske, P. Dynamic capabilities and sustainable supply chain management. Int. J. Phys. Distrib. Logist. Manag. 2012, 42, 372-387. [CrossRef]

59. Epstein, M.J.; Roy, M.J. Sustainability in action: Identifying and measuring the key performance drivers. Long Range Plan. 2001, 34, 585-604. [CrossRef]

60. Campion, N.; Thiel, C.L.; Woods, N.C.; Swanzy, L.; Landis, A.E.; Bilec, M.M. Sustainable healthcare and environmental life-cycle impacts of disposable supplies: A focus on disposable custom packs. J. Clean. Prod. 2015, 94, 46-55. [CrossRef]

61. Russo, M.V.; Fouts, P.A. A resource-based perspective on corporate environmental performance and profitability. Acad. Manag. J. 1997, 40, 534-559.

62. Mani, V.; Gunasekaran, A.; Papadopoulos, T.; Hazen, B.; Dubey, R. Supply chain social sustainability for developing nations: Evidence from India. Resour. Conserv. Recycl. 2016, 111, 42-52. [CrossRef]

63. Chen, I.J.; Paulraj, A. Towards a theory of supply chain management: the constructs and measurements. J. Oper. Manag. 2004, 22, 119-150. [CrossRef]

64. Inghels, D.; Dullaert, W.; Bloemhof, J. A model for improving sustainable green waste recovery. Resour. Conserv. Recycl. 2016, 110, 61-73. [CrossRef]

65. Carter, C.R.; Rogers, D.S. A framework of sustainable supply chain management: Moving toward new theory. Int.J. Phys. Distrib. Logist. Manag. 2008, 38, 360-387. [CrossRef]

66. Rotmans, J.; Loorbach, D. Complexity and transition management. J. Ind. Ecol. 2009, 13, 84-196. [CrossRef]

67. Machado, C.M.; Scavarda, A.; Vaccaro, G.; Korzenowski, A.L.; Batista, E. Analysis of hospital's sustainability: Economical, environmental, and social lenses. In Proceedings of the 2015 Industrial and Systems Engineering Research Conference, Nashville, TN, USA, 30 May-2 June 2015.

68. Liamputtong, P. Qualitative Research Methods; Oxford University Press: Oxford, UK, 2013.

69. World Health Organization. Technical Brief: HIV Patient Monitoring and Case Surveillance: Adapting and Implementing New Recommendations on HIV Patient Monitoring; World Health Organization: Geneva, Switzerland, 2017.

70. Unger, S.; Landis, A. Assessing the environmental, human health, and economic impacts of reprocessed medical devices in a Phoenix hospital's supply chain. J. Clean. Prod. 2016, 112, 1995-2003. [CrossRef]

71. Manogaran, G.; Thota, C.; Lopez, D.; Sundarasekar, R. Big data security intelligence for healthcare industry 4.0. In Cybersecurity for Industry 4.0; Springer International Publishing: Berlin, Germany, 2017; pp. 103-126.

72. Thuemmler, C.; Bai, C. Health 4.0: Application of Industry 4.0 Design Principles in Future Asthma Management. In Health 4.0: How Virtualization and Big Data Are Revolutionizing Healthcare; Springer International Publishing: Berlin, Germany, 2017; pp. 23-37.

73. Wang, Y.; Kung, L.; Wang, W.Y.C.; Cegielski, C.G. An integrated big data analytics-enabled transformation model: Application to health care. Inf. Manag. 2017. [CrossRef]

74. Rosca, E.; Arnold, M.; Bendul, J.C. Business models for sustainable innovation-An empirical analysis of frugal products and services. J. Clean. Prod. 2016. [CrossRef]

75. Robert, G.B.; Anderson, J.E.; Burnett, S.J.; Aase, K.; Andersson-Gare, B.; Fulop, N.J. A longitudinal, multi-level comparative study of quality and safety in European hospitals: The QUASER study protocol. BMC Health Serv. Res. 2011, 11, 285. [CrossRef] 
76. Lapointe, L.; Mignerat, M.; Vedel, I. The IT productivity paradox in health: A stakeholder's perspective. Int. J. Med. Inf. 2011, 80, 102-115. [CrossRef]

77. Gaustad, G.; Krystofik, M.; Bustamante, M.; Badami, K. Circular economy strategies for mitigating critical material supply issues. Resour. Conserv. Recycl. 2017. [CrossRef]

78. Schor, J.B. Born to Buy: The Commercialized Child and the New Consumer Cult; Simon and Schuster: New York, NY, USA, 2014.

79. Oftelie, A. Leadership in the new era of convergence. Kennedy Sch. Rev. 2015, 15, 113-120.

80. Angeli, F.; Jaiswal, A.K. Business model innovation for inclusive health care delivery at the bottom of the pyramid. Organ. Environ. 2016, 29, 486-507. [CrossRef]

81. Bonciu, F.; Balgar, A.C. Sharing economy as a contributor to sustainable growth, an EU perspective. Rom. J. Eur. Aff. 2016, 16, 36.

82. Boons, F.; Montalvo, C.; Quist, J.; Wagner, M. Sustainable innovation, business frameworks and economic performance: an overview. J. Clean. Prod. 2013, 45, 1-8. [CrossRef]

83. Miller, B.J.; Moore, D.W.; Schmidt, C.W., Jr. Telemedicine and the sharing economy: The "Uber" for healthcare. Am. J. Manag. Care 2016, 22, 420-422.

84. Geels, F.W. The impact of the financial-economic crisis on sustainability transitions: Financial investment, governance and public discourse. Environ. Innov. Soc. Transit. 2013, 6, 67-95. [CrossRef]

85. Christensen, C.M.; Grossman, J.H.; Hwang, J. The Innovator's Prescription. Soundview Executive Book Summaries. Available online: https:/ / www.lumc.nl/sub/9300/att/1402060248071959.pdf (accessed on 2 November 2017).

(C) 2018 by the authors. Licensee MDPI, Basel, Switzerland. This article is an open access article distributed under the terms and conditions of the Creative Commons Attribution (CC BY) license (http://creativecommons.org/licenses/by/4.0/). 